\title{
EARTH OBSERVATIONS AS A TOOL FOR DETECTING AND MONITORING POTENTIAL ENVIRONMENTAL VIOLATIONS AND POLICY IMPLEMENTATION
}

\author{
P. Patias ${ }^{1 *}$, G. Mallinis ${ }^{1}$, V. Tsioukas ${ }^{1}$, Ch. Georgiadis ${ }^{1}$, D. Kaimaris ${ }^{1}$, M. Tassopoulou ${ }^{1}$, N. Verde ${ }^{1}$, M. Dohr ${ }^{2}$, M. Riffler ${ }^{2}$ \\ ${ }^{1}$ Aristotle University of Thessaloniki, Laboratory of Photogrammetry and Remote Sensing, Thessaloniki, Greece - patias@auth.gr \\ ${ }^{2}$ Geoville Information Systems and Data Processing GmbH, Innsbruck, Austria
}

Commission III, WG III/6, WG III/7

KEY WORDS: Sentinel-2, Change - Detection, Time Series, Image Analysis, Object - Based

\begin{abstract}
:
In recent years advances in Earth Observation (EO) have increased our ability to inventory, monitor, and understand Earth's natural and artificial ecosystems. In particular, recent technological developments in the instrument characteristics of the remote sensing systems enabled large-scale usage of EO in environmental governance and protection. Remote sensing can be a potent tool employed in the field of environmental compliance. However, to extract and distribute relevant information to potential stakeholders, simple, yet efficient and robust approaches are needed. The focus of our research is the development of EO algorithms and the corresponding EO processing chains that could be used operationally for providing cost-efficient information to end-users to address environmental compliance and tackle environmental violations over specific thematic domains using freely available Copernicus data. The EO algorithms and the relevant EO processing chains have been developed as part of the EU-H2020 funded project: "EnviroLENSCopernicus for environmental law enforcement support" where the demonstration area of our approach is in the Montenegro - Albania border. The case considers several sites along the border to Albania, from the coastal area of Velika Plaža to the North Lake Skadar National Park. All sites have been designated in the past as protected areas, due to their rich biodiversity and threatened habitats. The focus of this contribution is on the deforestation detection processing chain. The developed EO processing chains rely on the use and analysis of multi-temporal Sentinel-2 images, while it adopts an object-based perspective for detecting, quantifying, and mapping potential environmental violations.
\end{abstract}

\section{INTRODUCTION}

\subsection{Remote Sensing and Environmental Law enforcement}

Environmental law, as a separate body of law, is an evolution of the $20^{\text {th }}$ century (Richard, 2006). More specifically, the need for establishing rules for the protection of the environment and the development of control mechanisms to implement and enforce environmental regulations and ensure compliance with environmental law did not occur before the 1960s.

Since the 1970s, environmental law had a considerable impact on national policies. In the last 40 years, the global community has embraced a significant number of environmental regulations and directives to ensure the efficiency of natural resources and to safeguard human health and ecosystems' consistency, improving citizens' quality of life.

Currently, more than $8 \%$ of the European Union's legislation is dedicated to environmental protection, covering all environmental sectors, including water, air, nature, waste, chemicals, biodiversity, and others.

The imposed environmental rules deal with issues such as environmental impact assessment, ensuring citizens, NGOs, and other group communities legal right to access environmental information and helping public authorities and policymakers to make decisions and prevent environmental damage.

However, environmental legislation on the statute book counts for little if it is not properly implemented and enforced (European Commission, 2012). Failure to implement legislation in a timely and effective way can result in considerable environmental, economic, and social consequences (European Commission, 2012). Namely, according to (UNEP and INTERPOL, 2016), silent and unsolved environmental crimes result in a global annual cost of 91-258 billion USD (2016), which corresponds to a $26 \%$ increase from previous estimates in 2014 . Moreover, environmental crimes are rising by $5-7 \%$ annually, which is equal to 2 - 3 times the corresponding rising rate of the global economy GDP. (Molino, 1995). This difficulty which is a common denominator of most environmental crimes generates serious doubts that undermine the enforcement of environmental law. The results are devastating for the environment and local economies and the main challenge now for the global community is how to implement the existing environmental regulations effectively rather than devise new legislation.

To overcome these barriers, the key priority for global research and development is to provide ready-to-access scientific evidence to support environmental law enforcement. Within that context, Remote Sensing is a powerful tool that can fulfil the ever-growing demand for reliable, on time and easy to understand information to policymakers, stakeholders, and the jurisdictional sector. Specifically, the technological advances in Earth Observation have increased the temporal, spectral, spatial, and radiometric characteristics of the remote sensing imagery. The derived almost continuous times series of satellite data of extended coverage and higher resolutions can now be utilized in environmental governance and protection.

However, while global initiatives and research projects are currently focusing on streamlining the use of remote sensing data to quantify changes in the environmental resources, challenges still exist on the large-scale usage of the results for the environmental law enforcement. This reliable information can provide solid evidence to combat environmental crime. However, the capabilities of remote sensing are relatively new to the legal sector, and according to (Kroker, 2014) the evidentiary potential of Remote Sensing analysis currently appears not to be fully exploited by international criminal justice mechanisms.

After having realized the gap between the hundreds of legal documents and compliance with the law, European Union has

\footnotetext{
* Corresponding author
} 
adopted the $7^{\text {th }}$ Environment Action Programme (EAP) to 2020, which consists of nine objectives - actions to ensure compliance of EU Member States with environmental legislation (Čavoški, 2019). Specifically, the EU recognizes the need for better access to justice in environmental matters, which can be achieved by utilizing the existing knowledge on monitoring and reporting the environment. Moreover, the proposed actions encourage the cooperation between remote sensing analysts and judicial authorities to provide scientific evidence for environmental violations.

The most powerful tool to implement this plan is the European Commission Copernicus satellite programme which was developed to provide accessible information at no cost about the status of the environment based on satellite EO Data. Particularly, the main source of information is the Copernicus Sentinel-2 mission which supports the monitoring of land use and land change by delivering high spatial resolution optical satellite imagery at $10 \mathrm{~m}$ spatial resolution (4 bands), $20 \mathrm{~m}$ spatial resolution ( 6 bands), and $60 \mathrm{~m}$ spatial resolution ( 3 bands). Furthermore, the short revisiting intervals of 5 to 10 days will generate consistent time series that will allow the monitoring of changes over large areas difficult to monitor using conventional methods. The data are available through the five DIAS online cloud-based platforms or the Conventional Data Hubs (i.e., Copernicus Open Access Hub, Sentinel Hub by Sinergise, Copernicus Online Data Access, and more). Copernicus services cover six thematic areas: atmosphere, marine environment, land monitoring, climate change, emergency management, and security.

\subsection{The EnviroLENS research programme}

The aim of the EU-H2020 funded project "EnviroLENS Copernicus for environmental law enforcement support" (eLENS) is to utilize the Copernicus EO capabilities in order to meet the requirements of the European jurisdictional sector for ready-to-access evidence and scenario information on environmental situations and violations (https://envirolens.eu/). Specifically, eLENS's main objectives are to support various end-users including corporate law firms, public authorities, and NGOs active in the field of environmental law enforcement on the evidence data gathering process for environmental infringements, and to foster data-driven decision-making policies.

The eLENS project aims to develop four functional groups of services including corporate services, legal services, society services and, finally, the EO services. Focusing on the EO services, the proposed alert, monitoring, and historical services, will provide near real-time high-quality information for the effective environmental protection while reducing cost and time efforts for the user. The aforementioned information is derived by fully automated Big-Data production processes, capable to fully exploit the Copernicus missions, integrated with in-situ data. Finally, in order to support very local events on a large scale, the service will incorporate very high-resolution datasets of third-party satellite missions.

Within the framework of the eLENS project, the current study focuses on the development of the EO algorithms and the corresponding EO processing chains that could be used operationally for providing cost-efficient information to the enduser to tackle environmental violations over specific thematic domains using freely available Copernicus data.

To demonstrate the capabilities of the developed EO algorithms, several sites were selected across the Montenegro - Albania Border from the coastal area of Velika Plaža to the North Lake Skadar National Park. All sites have been designated in the past as protected areas due to their rich biodiversity and threatened habitats. These regions are subject to significant and often persistent environmental pressures, including illegal logging and encroaching urbanization due to various infrastructure development projects.

\section{STUDY AREA}

The selected sites (Figure 1) are serving as a pilot for the demonstration of the capabilities of the developed EO algorithm. They aim to fulfil the requirements of the Center for the Protection and Research of Birds of Montenegro (CZIP), which is a major stakeholder of the project. Specifically, according to the user needs, the selected sites are facing serious environmental threats, and there is a need for monitoring multiple environmental variables including among other construction, illegal logging, and water level fluctuations.

Stretching about $12 \mathrm{~km}$, the selected site of Velika Plaža in Delta Bojane is among the longest beaches in Europe. With its rising popularity has come an influx of construction projects and increased pressure from human activities for both beach and hinterland.

Furthermore, the selected site of Ulcinj Salina was recently designated as a protected area since the collapse of the salt businesses that were operating in the area until 2013. The businesses' infrastructure of the site, such as dikes channels, had the positive benefit of helping migratory birds to create a habitat. However, since the closure of the business, the area has fallen into disrepair along with its quality as a habitat, and the recent designation aims to restore and maintain the quality of the habitat.

Nikšićko polje is another critical habitat for wildlife. Spanning an area of about 4.800 hectares in the western part of the country, Nikšićko polje is the largest karst field in Montenegro.

Finally, Lake Skadar is the third designated site that we are focusing on in our research. Two-thirds of the Lake is on the Montenegrin side of the border, with the remaining area spanning across the border in Albania. Varying seasonally between 37.000ha and 53.000ha, it is the largest lake on the Balkan Peninsula and is famous for its diversity of both flora and fauna. The National Park of Lake Skadar established in 1983 protects an area of 40.000 ha on the Montenegrin side. The area is under threat from illegal logging and encroaching urbanization and construction projects.

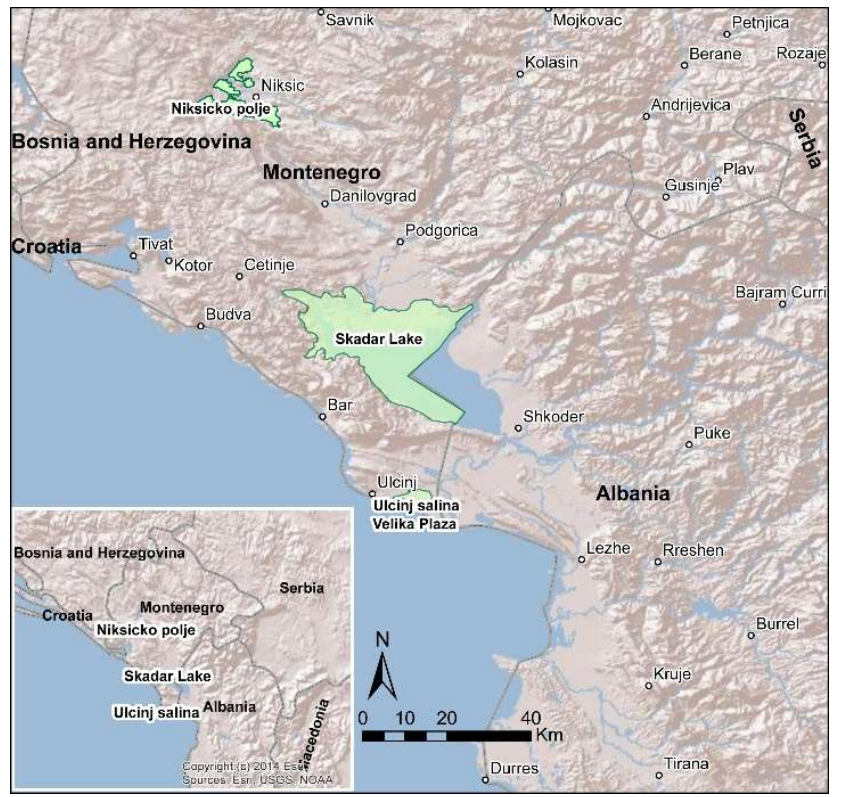

Figure 1. The selected sites in the Montenegro - Albania border 


\section{METHODOLOGY}

\subsection{Overall workflow}

In order to compensate for the relatively short length of existing time-series datasets of the Sentinel-2 sensor, the developed EO processing chain relied on the use and analysis of bi-temporal images. The approach follows an object-based perspective for detecting, quantifying, and mapping potential environmental violations.

Initially, a set of spectral indices is calculated for a bi-temporal pair of Sentinel-2 images. Within the boundary of each protected site, areas likely to experience forest disturbance and deforestation events are retrieved from a global-scale existing geospatial dataset providing information on tree canopy cover. The forest areas, within the protected area, serve as the base unit (i.e., object), for the subsequent analysis. Individual per-pixel spectral index changes within each object are considered for estimating the mean spectral change within each object.

Finally, the difference from the mean is calculated for every pixel within each object, quantifying each's pixel deviation compared to the average temporal change within each object.

\subsection{Remote sensing data and pre-processing}

The Sentinel-2 mission is based on a constellation of two satellites providing systematic global acquisitions of mediumhigh spatial resolution multispectral imagery.

Sentinel-2A was launched in 2015 , followed by the Sentinel-2B launch in 2017 as a part of the Copernicus programme, previously known as GMES (Global Monitoring for Environment and Security).

Sentinel-2A and Sentinel-2B record reflectance over 13 spectral bands covering the visible to shortwave infrared (SWIR) electromagnetic spectrum from 10 to $60 \mathrm{~m}$ of spatial resolution.

The constellation has a wide swath and a revisiting time of 5 days over the equator, making the data particularly appealing for applications related to the detection and monitoring of changes over Earth's surface (Berger et al. 2012).

In our study, individual granules corresponding to $34 \mathrm{TCM}$ and $34 \mathrm{TCN}$ tiles, processed at level $1 \mathrm{C}$ were accessed through the Copernicus Open Access Hub.

Since Sentinel-2 1C provides Top-Of-Atmosphere (TOA) Level$1 \mathrm{C}$ orthoimage products, atmospheric and topographic corrections were performed with the Sen2Cor processor to convert radiometric values to surface reflectance.

The robustness of the deforestation detection approach has been evaluated using both a bi-temporal pair of images as well as multi-date composite synthetic images.

For the first experiment, Sentinel-2A imagery acquired on $15^{\text {th }}$ of -July $2015,9^{\text {th }}$ of July 2016 , and Sentinel-2B acquired on $29^{\text {th }}$ of June 2019 were used (Figure 2).
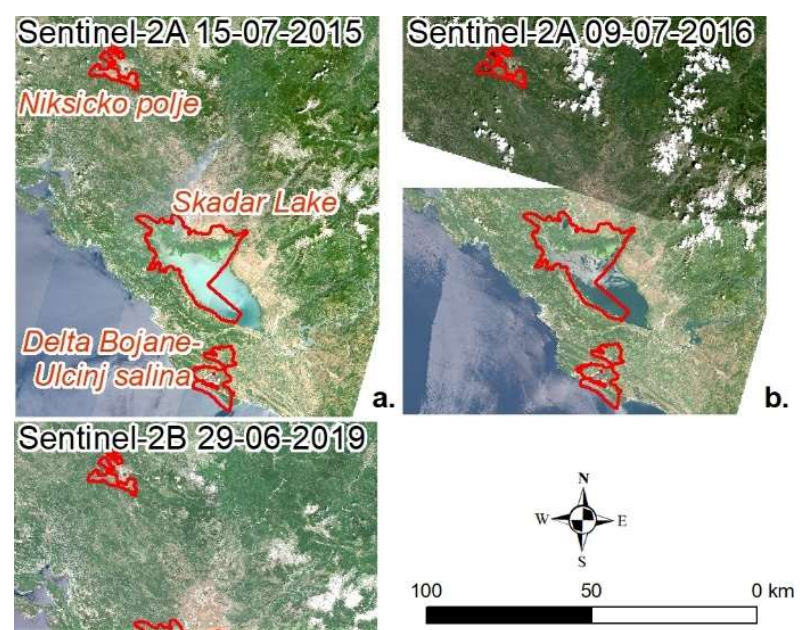

Figure 2. T34 TCM and TCN single-scene tiles processed over the three selected sites in summer 2015 (a), 2016 (b), and 2019 (c) for bi-temporal detection of deforestation.

For the second experiment, annual image composites (Figure 3) were generated for 2015,2016, 2017, 2018, and 2019.
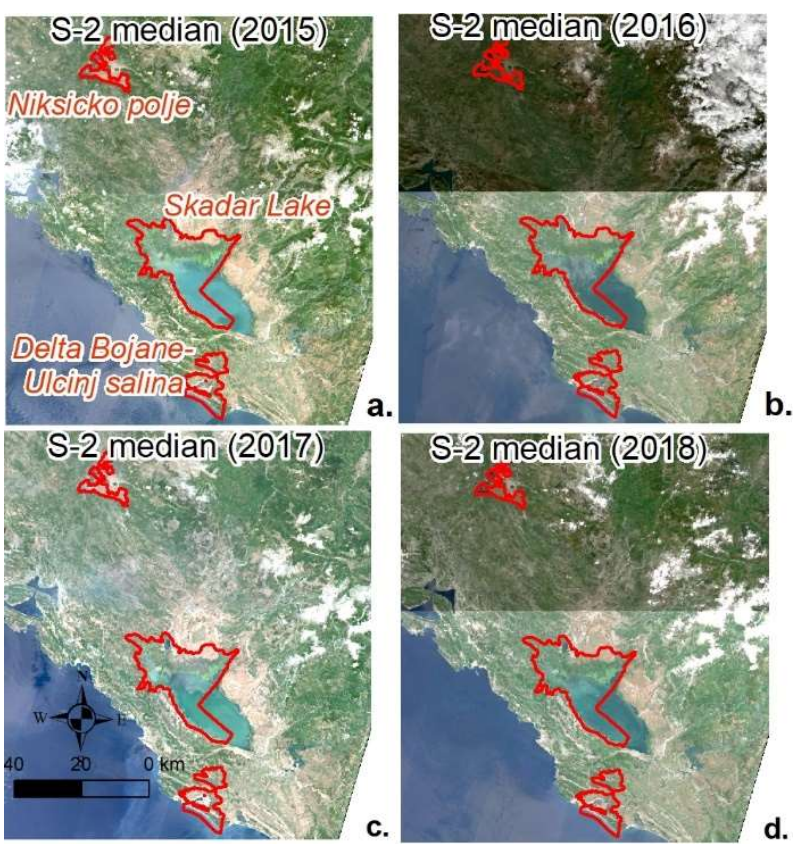

Figure 3. T34 TCM and TCN median composites over the three selected sites for 2015 (a), 2016 (b), 2017 (c) and 2018 (d)

In the composite approach, a new synthetic-image per annual period is created using the median values of all Sentinel-2 images having a cloud-cover less than $25 \%$.

While the median-composite-approach strongly depends on the available number of cloud-free images over the area of interest, it has been shown to provide robust, consistent results over different studies and remote sensing data (Griffiths et al., 2019). 


\subsection{Spectral indices estimation}

Using spectral indices representing ratios and/or linear combinations of the original spectral bands from remotely sensed images are considered a standard spectral transformation employed in change detection studies.

Among the wide range of existing spectral indices available in the literature, we originally computed four indices, namely Modified Soil Adjusted Vegetation Index (MSAVI, Normalized Burn Ratio (NBR), Normalized Difference Vegetation Index (NDVI), and Ratio Vegetation Index (RVI). Following a preliminary visual/exploratory analysis, we identified that NBR, considering the near-infrared and shortwave infrared part of the spectrum, provided the highest discrimination ability among the indices tested for detecting forest disturbance events.

Subsequently, NBR was calculated by the following computing formula (Key and Benson, 2006) for all images included in the dataset:

$$
N B R=\frac{N I R-S W I R}{N I R+S W I R}
$$

where $\quad N I R=$ Near InfraRed band of Sentinel-2

$S W I R=$ ShortWave InfrarRed band of Sentinel-2

\subsection{Baseline forest extent}

Vegetation canopy cover is an Essential Urban Variable (EUV) and is identified as an important variable for monitoring illegal logging, deforestation, and other environmental severe violations associated with the degradation of forest ecosystems. This EUV is defined as the share of ground covered by the vertical projection of the canopy. Canopy cover percentage is also the essential parameter for the definition of forest extent (Chazdon et al., 2016). In this respect, the GFCC Tree Cover Multi-Year Global dataset that contains estimates of the percentage of horizontal ground in each $30-\mathrm{m}$ pixel covered by woody vegetation (Sexton et al., 2013) was used for selecting the reference samples for identifying forest extent within the study area.

\subsection{Detection of pixels exhibiting forest disturbance}

For each pair of images employed in the study, the differenced Normalized Burn Ratio (dNBR) index was calculated. Subsequently, for all the pixels located within the forest extent of each protected area (i.e., object), the difference from the object's average dNBR was calculated and used for highlighting locations of deforestation events. Pixels in the difference images which were significantly different from the mean of the density function for each object were labelled as change in a hard-classification procedure.

\section{RESULTS}

Visual assessment (Figure 4 and Figure 5) of the Sentinel-2 composites and freely available VHR data support that the proposed approach to detect deforestation is efficient in identifying potential environmental violations, and is appropriate for the short time series currently available from the Sentinel-2 satellite constellation.

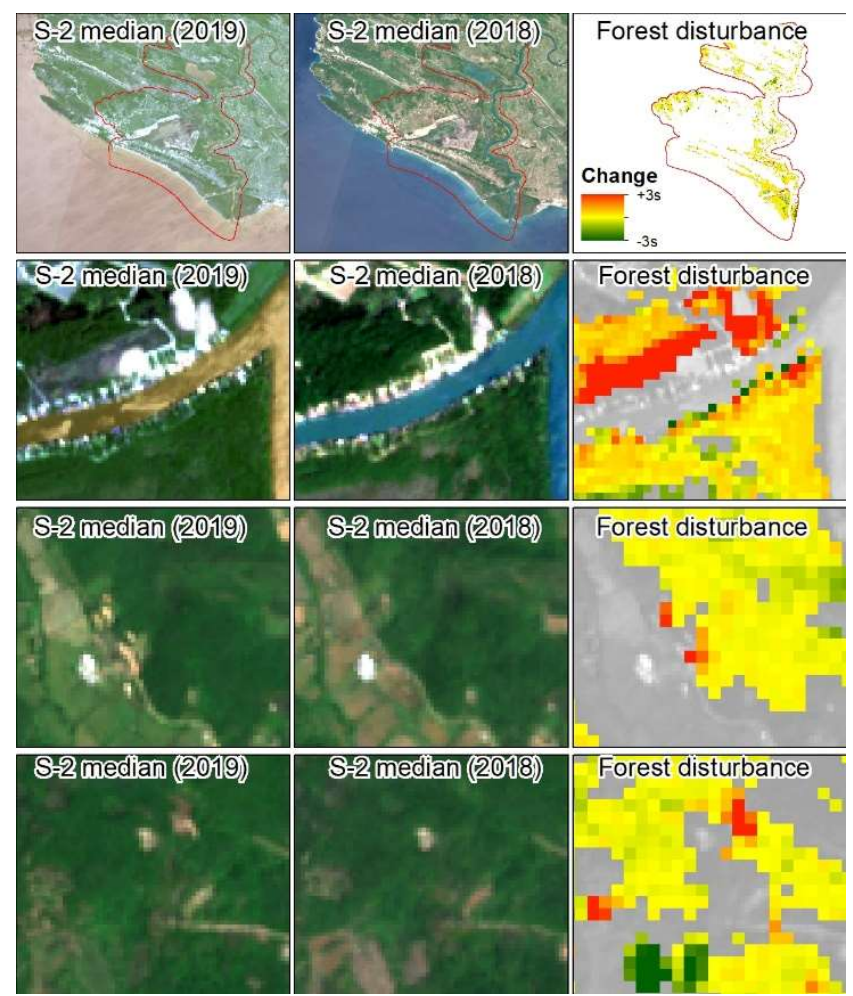

Figure 4. Deforestation detection among the 2019-2018 annual composites. Apart from forest removal (red color), the approach can also flag pixels experiencing afforestation (green pixels)

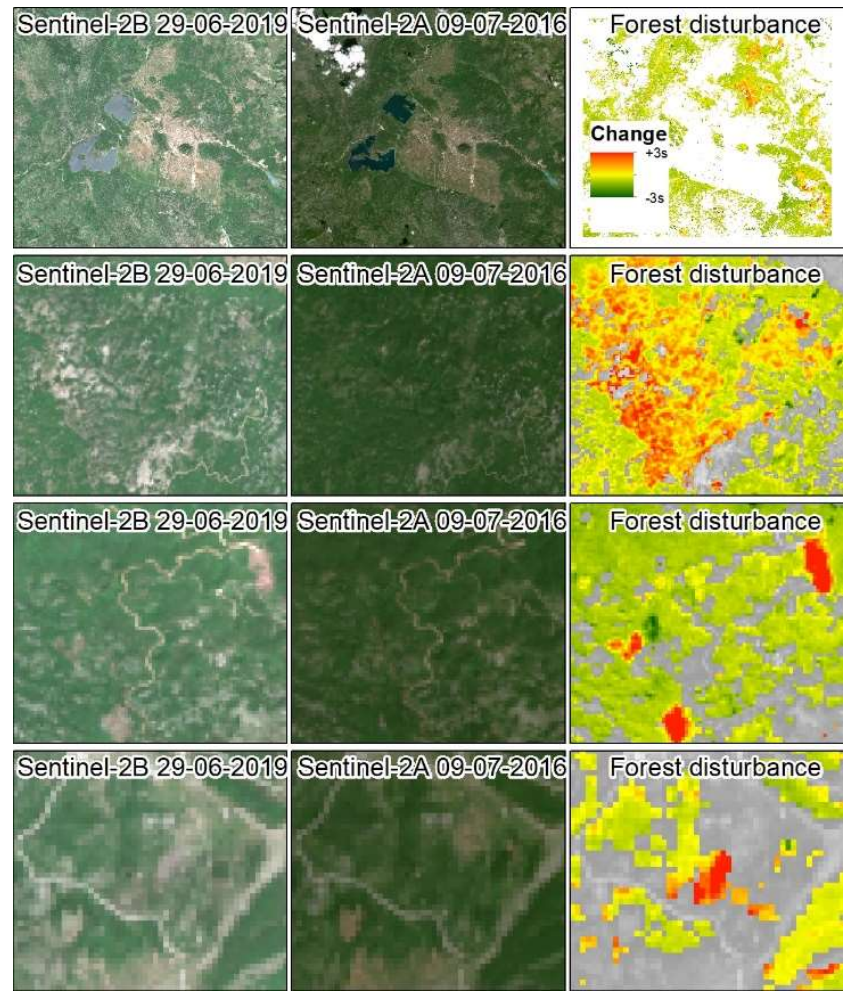

Figure 5. Deforestation detection based on the bi-temporal analysis of two single scenes acquired on 09-07-2016 and 29-

06-2019. Both small-scale and large deforestation events (yellow to red) are detected. 

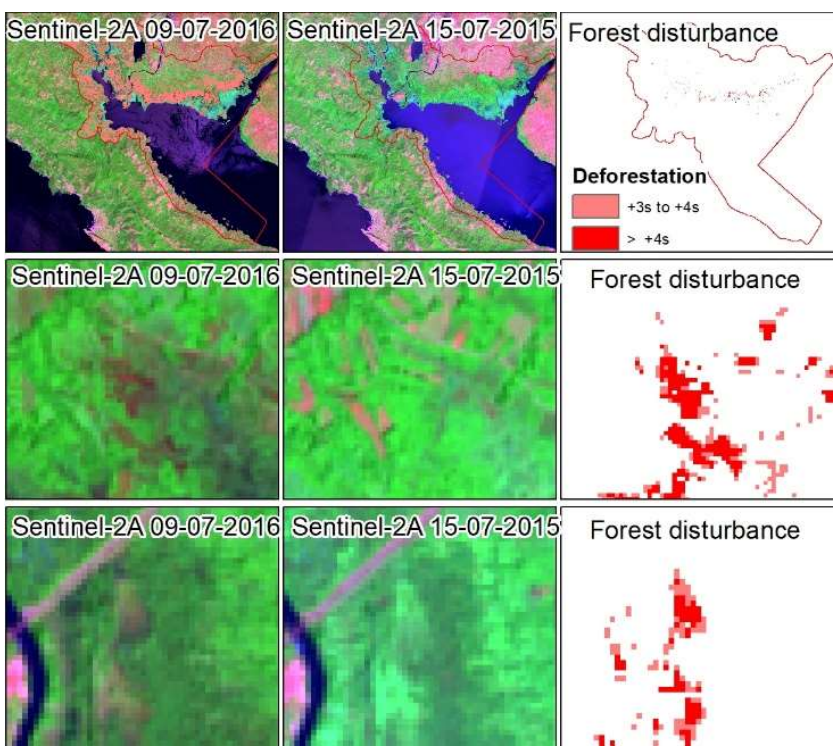

Forest disturbance

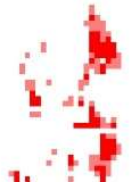

Figure 6. Deforestation detection based on the bi-temporal analysis of two single scenes acquired on 09-07-2016 and 1507-2015. A hard classification procedure is applied to delineate areas exhibiting forest disturbance

In addition to the visualization and qualitative appraisal of the changes, a hard classification approach (Figure 6) facilitates a quantitative assessment of the deforestation magnitude.

In the southern part of the study area, including the Velika Plaža and Ulcinj Salina sites, only 3\% of these sites experienced distinct vegetation losses from 2016 to 2019.

During the same period, in the forest area around the Skadar Lake again, $3 \%$ of the forest areas experienced vegetation losses.

Finally, in the northern part of the overall study area around the Nikšićko polje site, $4,73 \%$ of the forest extent in 2016 was destructed (spectral change of more than three standard deviations from the object's mean) according to the deforestation detection results. In this case, the slightly greater changes, can be linked to fires spreading over the low forest cover areas during 2016-2019, most likely due to the excess human pressure and the requirements for new grassland areas.

From the multitemporal analysis of the annual composites, it is evident that the overall landscape in all three sites exhibits little if any change in terms of forest removal (Table 1).

\begin{tabular}{|c|c|c|c|}
\hline \multirow{2}{*}{ Time-period } & \multicolumn{3}{|c|}{ Study site } \\
\cline { 2 - 4 } & $\begin{array}{c}\text { Nikšićko } \\
\text { polje }\end{array}$ & Lake Skadar & $\begin{array}{c}\text { Ulcinj } \\
\text { Salina/ } \\
\text { Velika Plaža }\end{array}$ \\
$2018-2019$ & $0,51 \%$ & $0,10 \%$ & $0,20 \%$ \\
$2017-2018$ & $0,47 \%$ & $0,03 \%$ & $0,07 \%$ \\
$2016-2017$ & $0,32 \%$ & $0,39 \%$ & $0,32 \%$ \\
$2015-2016$ & $1,54 \%$ & $0,11 \%$ & $0,16 \%$ \\
\hline
\end{tabular}

Table 1. Deforestation detection within each of the test sites (percent of total area)

Nevertheless, a major constraint for the evaluation of the results relates to the lack of in-situ or larger scale reference data (as well as for training the algorithm during the development phase). The validation of the results was performed visually by comparing the classification result with Google Earth high-resolution imagery. Preferably, a detailed accuracy assessment with in-situ data regarding the deforestation extent and analytical methods should have been followed-however this has not been feasible in the specific study due to limited data avalailabitly from local stakeholders.

The baseline canopy cover map used for the delineation of the forest extent is also likely to include potential inaccuracies, that might had affected the overall accuracy of our approach. This is supported by Figure 7 (middle row), in which a number of pixels within the Buna river are characterized as likely deforestation areas, indicating that in the baseline map they were assigned as forest areas.

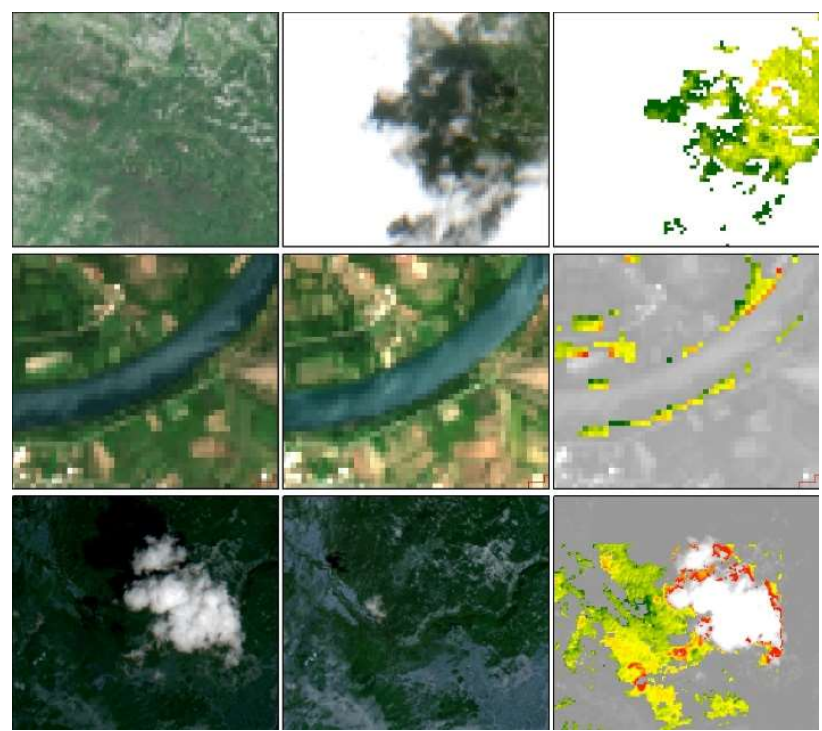

Figure 7. Misclassification due to errors present in the classification process related to cloud shadows (upper row), misregistration (middle row) and clouds (lower row)

In addition, as it can be observed in Figure 7, errors are introduced in the final change detection product due to the misregistration of Sentinel-2 images (middle row). Several studies have also identified that Sentinel-2 orthoimages may have geolocation offset errors, especially at higher spatial scale $(10 \mathrm{~m}$ bands) (Kukawska et al., 2017; Pereira-Pires et al., 2020; Yan et al., 2018). The effect of the misregistration might be important when employing multi-temporal Sentinel-2A data for applications that require precise sub-pixel registration suggesting the use of additional pre-processing steps (Pereira-Pires et al., 2020; Yan et al., 2018).

Finally, the Sen2Cor processor, as indicated in previous studies, presents moderate accuracy in cloud/shadow removal, including over-detection of clouds over bright targets and degraded performance for scenes with low clouds (Baetens et al., 2019).

However, an accurate cloud/shadow mask should be a prerequisite to enable automatic processing of the large data volumes of the freely available Sentinel- 2 and Landsat- 8 images (Frantz et al., 2018).

\section{CONCLUSION}

Violations of environmental laws or contractual obligations, which result in physical, chemical, or biological alterations of landscapes or ecosystems, can be documented through EO in spatially explicit and quantitative means. This information can be used to fulfil reporting requirements to international environmental treaties, enforce policy and promote compliance to regulations, promote corporate environmental policy, detect and avoid environmental crimes, provide supporting material to 
be used as evidence in court and contribute to environmental impact assessment among others. In this study, we presented an approach for operational multi-temporal detection of deforestation using Sentinel-2 imagery. Initially, a differenced spectral index is calculated for any pair of images. The method considers the forest area under study as an individual object of interest, calculating variability of changes at pixel level.

The approach assumes that that pixels in the difference image, which are significantly different from the mean of the density function within each object, can be labelled as forest disturbance events. The robustness of the approach was evaluated over different years and image products (i.e., single scenes and annual composites). Although the validation approach did not rely on standard accuracy assessment procedures due to the lack of reference data, the visual assessment of the results demonstrates the potential for generating deforestation alerts over environmentally sensitive areas. In the future, the availability of more extended Sentinel-2 time-series datasets will also facilitate the evaluation of time-series methodologies based on change analysis and detection of anomalies over extended periods.

\section{ACKNOWLEDGEMENTS}

The work leading to these results has been supported by the H2020 project "enviroLENS: Copernicus for environmental law enforcement support, funded from the European Union's Horizon 2020 research and innovation programme under grant agreement No. 821918.

\section{REFERENCES}

Baetens, L., Desjardins, C., Hagolle, O., 2019. Validation of Copernicus Sentinel-2 Cloud Masks Obtained from MAJA, Sen2Cor, and FMask Processors Using Reference Cloud Masks Generated with a Supervised Active Learning Procedure. Remote Sens. doi:10.3390/rs11040433

Čavoški, A., 2019. EU environmental compliance assurance. Environ. Law Rev. 21, 111-118. doi:10.1177/1461452918824508

Chazdon, R.L., Brancalion, P.H.S., Laestadius, L., BennettCurry, A., Buckingham, K., Kumar, C., Moll-Rocek, J., Vieira, I.C.G., Wilson, S.J., 2016. When is a forest a forest? Forest concepts and definitions in the era of forest and landscape restoration. Ambio 45, 538-550. doi:10.1007/s13280-016-0772-y

European Commission, 2012. Implementing environment legislation [WWW Document]. Environ. Eur.

Frantz, D., Haß, E., Uhl, A., Stoffels, J., Hill, J., 2018. Improvement of the Fmask algorithm for Sentinel-2 images: Separating clouds from bright surfaces based on parallax effects. Remote Sens. Environ. 215, 471-481. doi:https://doi.org/10.1016/j.rse.2018.04.046

Griffiths, P., Nendel, C., Hostert, P., 2019. Intra-annual reflectance composites from Sentinel-2 and Landsat for national-scale crop and land cover mapping. Remote Sens. Environ. 220, 135-151. doi:https://doi.org/10.1016/j.rse.2018.10.031

Key, C.H., Benson, N.C., 2006. Landscape Assessment: Ground measure of severity, the Composite Burn Index; and Remote sensing of severity, the Normalized Burn Ratio. Ogden, UT.

Kroker, P., 2014. Emerging Issues Facing the Use of Remote Sensing Evidence for International Criminal Justice. Cambridge.
Kukawska, E., Lewiński, S., Krupiński, M., Malinowski, R., Nowakowski, A., Rybicki, M., Kotarba, A., 2017. Multitemporal Sentinel-2 data - remarks and observations, in: 2017 9th International Workshop on the Analysis of Multitemporal Remote Sensing Images (MultiTemp). pp. $1-4$.

Molino, S., 1995. Practical Difficulties in Prosecuting Environmental Offenders, in: Gunningham, N., McKillop, S., Norberry, J., Criminology, A.I. of (Eds.), Environmental Crime. Conference Proceedings Series No. 26. Australian Institute of Criminology, Canberra.

Pereira-Pires, E.J., Aubard, V., Ribeiro, A.R., Fonseca, M.J., Silva, M.N.J., Mora, A., 2020. Semi-Automatic Methodology for Fire Break Maintenance Operations Detection with Sentinel-2 Imagery and Artificial Neural Network. Remote Sens. . doi:10.3390/rs12060909

Richard, J.L., 2006. The Making of Environmental Law, Paperback. ed. The University of Chicago Press, Chicago.

Sexton, J.O., Song, X.-P., Feng, M., Noojipady, P., Anand, A., Huang, C., Kim, D.-H., Collins, K.M., Channan, S., DiMiceli, C., Townshend, J.R., 2013. Global, 30-m resolution continuous fields of tree cover: Landsat-based rescaling of MODIS vegetation continuous fields with lidar-based estimates of error. Int. J. Digit. Earth 6, 427448. doi:10.1080/17538947.2013.786146

UNEP, INTERPOL, 2016. The Rise of Environmental Crime - A Growing Threat To Natural Resources Peace, Development And Security. UNEP, Nairobi, Kenya.

Yan, L., Roy, D.P., Li, Z., Zhang, H.K., Huang, H., 2018. Sentinel-2A multi-temporal misregistration characterization and an orbit-based sub-pixel registration methodology. Remote Sens. Environ. 215, 495-506. doi:https://doi.org/10.1016/j.rse.2018.04.021 